\title{
Study on the Mechanism of Gas Component Release for Biomass Pyrolysis
}

\author{
Hongtao Li*, Wang Li, Yunguang Ji, Shuqi Xue, Zhenhui Wang \\ School of Mechanical Engineering, Hebei University of Science and Technology, Shijiazhuang 050018, China
}

\begin{abstract}
Biomass energy utilization can solve the contradiction between economic development and energy and environment. Biomass pyrolysis technology is not only one of the thermochemical conversion technologies, but also the necessary stage of biomass gasification, which has become a hot academic research topic. Firstly, based on the pyrolysis experimental data of cellulose, hemicellulose and lignin, the analytical expressions of pyrolysis gas mass yields of different biomass components varying with temperature were obtained; then, the prediction of pyrolysis products was obtained by mass component superposition method, and the correction coefficient of biomass pyrolysis gas yield model was obtained based on the comparison between the average yield of biomass pyrolysis gas and the predicted value of pyrolysis products; finally, the gas release mechanism model of biomass pyrolysis was obtained. This study provides theoretical basis and technical support for the development of biomass utilization technology.
\end{abstract}

\section{Introduction}

With the depletion of fossil fuel resources and increasing environmental problems, how to alleviate the contradiction between economic development and energy and the environment has become a problem that all countries in the world must face. Biomass energy, as the fourth energy source after coal, oil and natural gas, has attracted wide attention from scholars at home and abroad because of its huge reserves and "carbon neutrality".

There are generally three ways to utilize biomass energy: physical conversion, thermochemical conversion and biological conversion. Gasification and pyrolysis are the two main thermochemical conversion technologies. As one of the most important biomass thermochemical conversion technologies, pyrolysis is also a necessary stage of biomass gasification, has become a hot academic research topic. However, due to the complex relationship between the composition and yield of pyrolysis products and biomass composition, pyrolysis temperature and heating rate, there is no universally recognized release mechanism for pyrolysis products. This paper is based on the pyrolysis gas production data of three components of biomass, cellulose, hemicellulose and lignin provided by reference[1]. Firstly, the relationship between temperature change and mass fraction of volatile gases produced by three components was obtained by data fitting method; secondly, the prediction of pyrolysis products was obtained by mass component superposition method; then, the revision coefficients of the model for the biology of elemental analysis was obtained by comparing the average yield of pyrolysis gases with the prediction of pyrolysis products.
Finally, the model for volatile gas evolution from biomass pyrolysis considering the influence of three components is obtained.

\section{Pyrolysis mechanism of biomass single component}

In view of the fact that the main components of biomass are cellulose, hemicellulose and lignin, the pyrolysis rules of each component were studied in this section.

\subsection{Cellulose pyrolysis mechanism}

Cellulose is the most abundant organic polymer in plant cell wall. It is a natural polymer of pyranose (a kind of hexacarbocyclic hydrocarbon). Three carbonyls in each pyranose ring can interact with each other to form intramolecular and intermolecular hydrogen bonds, which make cellulose have crystal structure, unique mechanical strength and chemical stability [2]. The main products of cellulose pyrolysis are $\mathrm{CO}, \mathrm{CO}_{2}, \mathrm{H}_{2}$ and $\mathrm{CH}_{4}$. The yield curve and fitting curve of cellulose pyrolysis products are shown in Fig. 1. It shows that: 1) when the reaction temperature is lower than $460^{\circ} \mathrm{C}$, the gas products of cellulose pyrolysis are mainly $\mathrm{CO}$ and $\mathrm{CO}_{2}$, the yield of the former is slightly higher than that of the latter, while the yields of $\mathrm{H}_{2}$ and $\mathrm{CH}_{4}$ are very low; 2) With the increase of temperature, the yields of $\mathrm{CO}$ and $\mathrm{CO}_{2}$ are gradually increasing, while the yields of $\mathrm{H}_{2}$ and $\mathrm{CH}_{4}$ are pyrolysis. 3) At $300 \sim 900^{\circ} \mathrm{C}$, the deviation between the fitting curve and the pyrolysis experimental data is little, and the fitting formula of pyrolysis products can better reflect the pyrolysis experiment.

\footnotetext{
* Corresponding author: LHT9542@163.com
} 


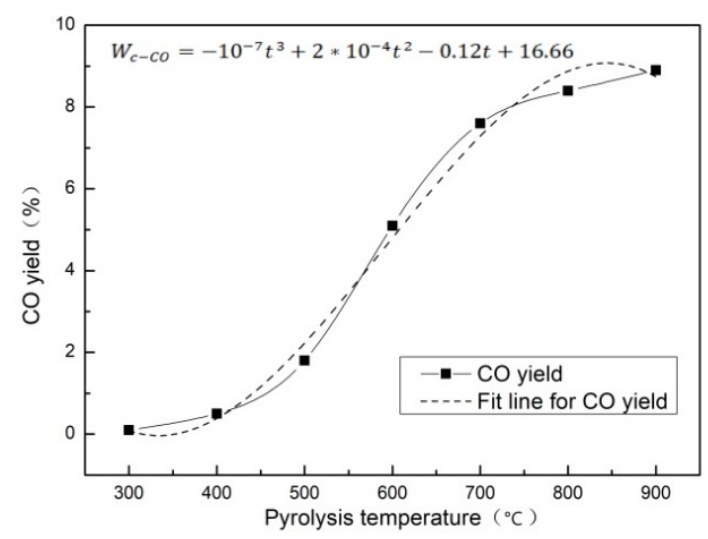

(A)

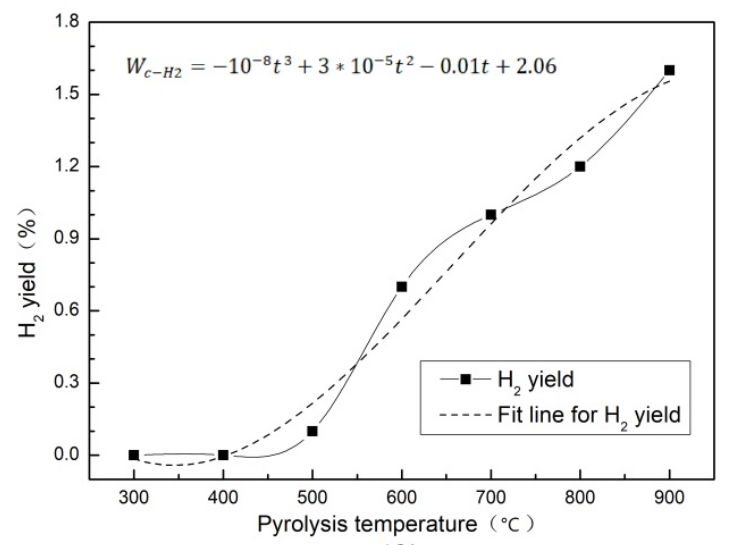

(C)

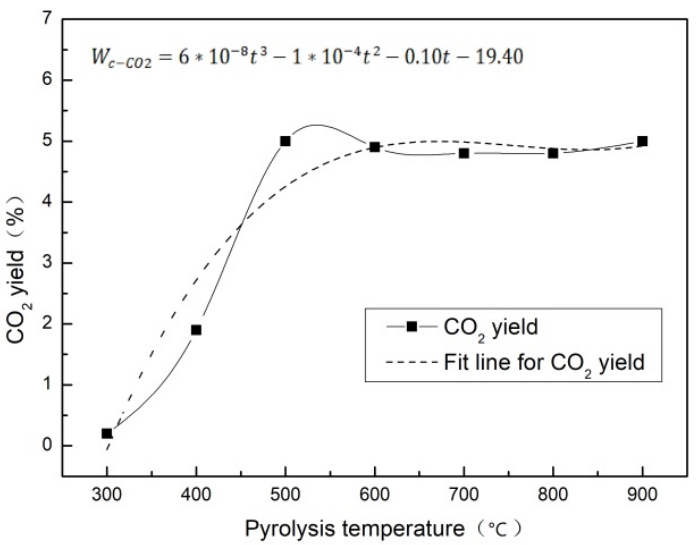

(B)

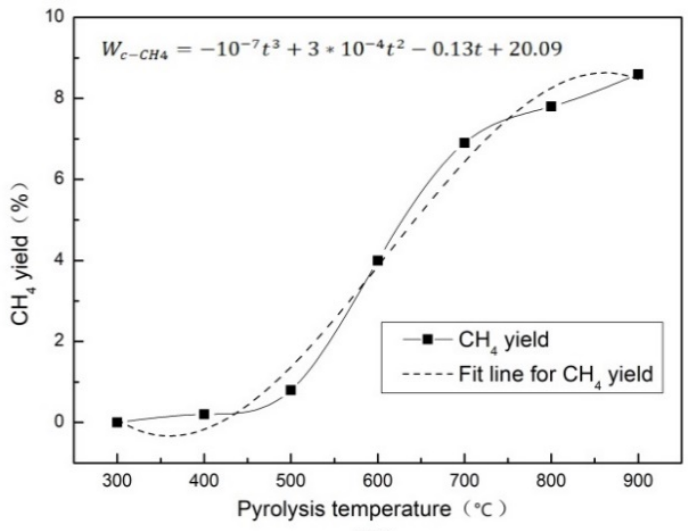

(D)

Fig. 1. The yield curve and fitting curve of cellulose pyrolysis products

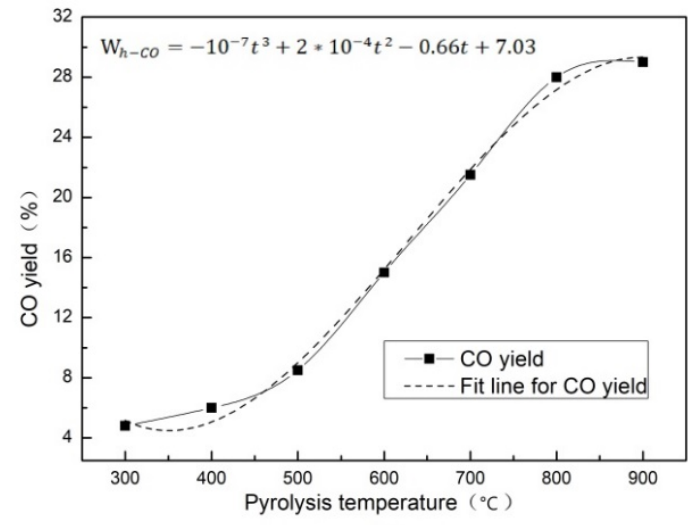

(A)

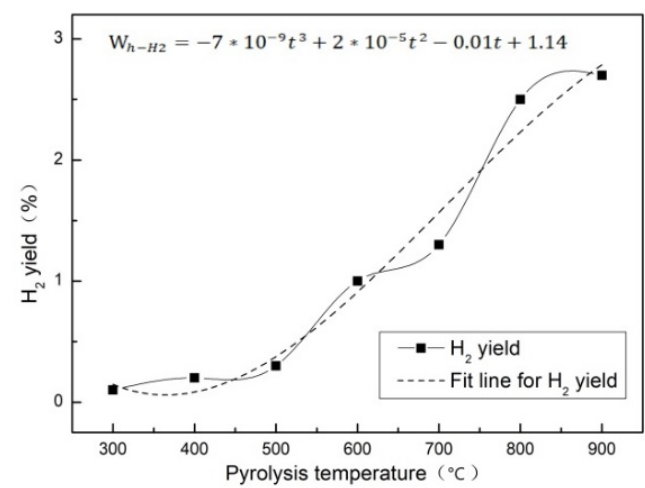

(C)

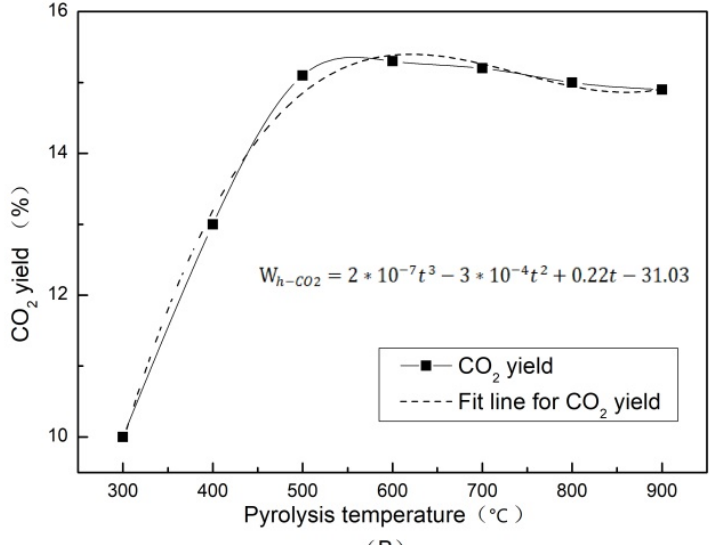

(B)

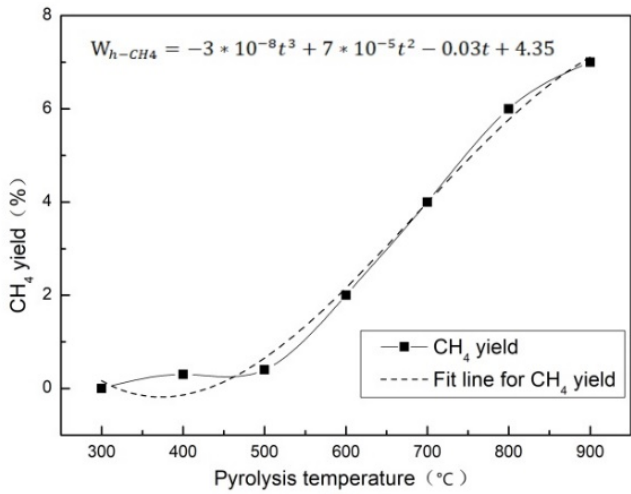

(D)

Fig. 2. The yield curve and fitting curve of hemicellulose pyrolysis products 


\subsection{Hemicellulose pyrolysis mechanism}

Hemicellulose encapsulates cellulose and bonds cellulose and lignin, which is an amorphous branchedchain polysaccharide structure. Different monomers such as glucose, galactose, mannose, xylose, arabinose and glucuronic acid are the basic structural elements that make up hemicelluloses [3].

The main components of hemicellulose pyrolysis gas are the same as cellulose. The yield curve and fitting curve of hemicellulose pyrolysis products are shown in Fig. 2. It shows that: 1) At $200 \sim 450^{\circ} \mathrm{C}$, the main components of hemicellulose pyrolysis gases are also $\mathrm{CO}$ and $\mathrm{CO}_{2}$, and the yields of both gases increase with the increase of temperature; 2) The yield of $\mathrm{CO}_{2}$ from hemicellulose pyrolysis at low temperature is significantly higher than that of carbon dioxide, and also higher than that of cellulose pyrolysis under the same conditions, but the yield of carbon dioxide is similar; 3 ) The $\mathrm{H}_{2}$ yield of hemicellulose pyrolysis is higher than that of cellulose, while the $\mathrm{CH}_{4}$ yield is slightly lower.
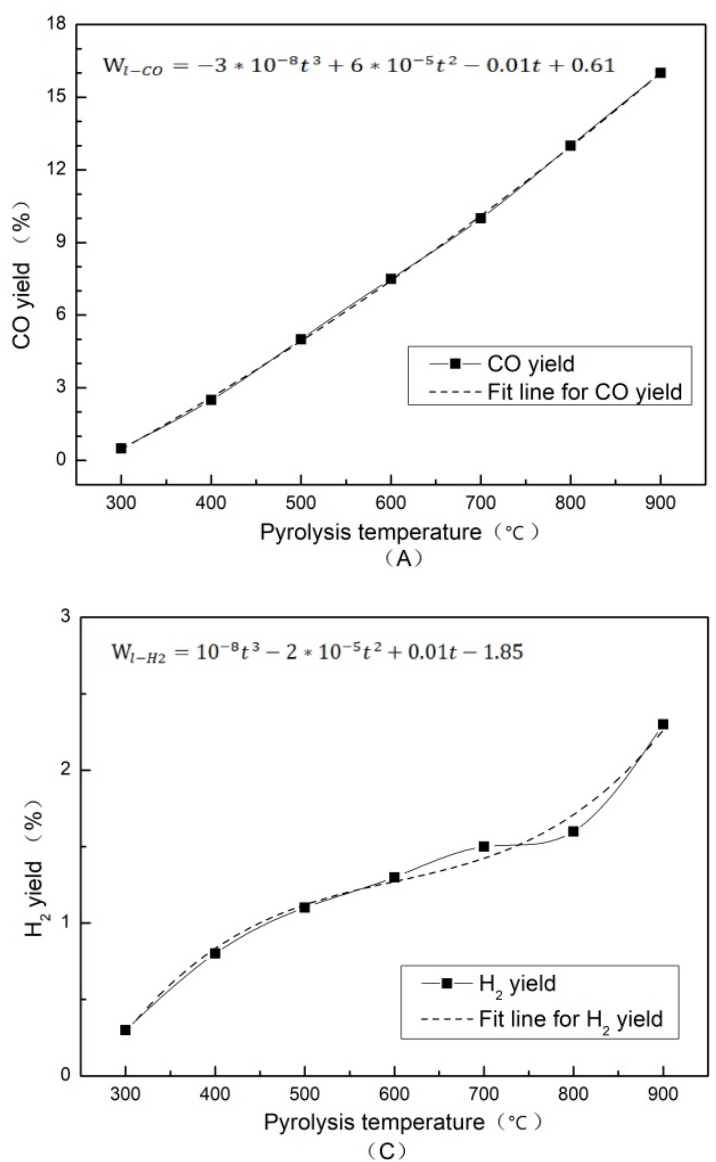

\subsection{Lignin pyrolysis mechanism}

Lignin is a natural amorphous structure polymer that gives plants a certain mechanical strength, which is about $15 \sim 30 \%$ of lignocellulosic biomass. In addition to its unique phenyl group, lignin is rich in functional groups such as alcohol hydrocarbon groups, phenol hydrocarbon groups, carbonyl groups, carboxyl groups and methoxy groups [4]. Its structural characteristics determine that the release characteristics of pyrolysis products are quite different from those of cellulose and hemicellulose.

The yield curve and fitting curve of Lignin pyrolysis products are shown in Fig. 3. It shows that: 1) When the pyrolysis temperature is lower than $450^{\circ} \mathrm{C}$, the main components of lignin pyrolysis gas products are $\mathrm{CO}$ and $\mathrm{CO}_{2}$, and the yield of $\mathrm{CO}$ at this time is close to that of cellulose and hemicellulose pyrolysis ; 2 ) At low temperature, there is almost no $\mathrm{H}_{2}$ and $\mathrm{CH}_{4}$ in lignin pyrolysis. With the increase of temperature, the yields of the two gases increase slowly.

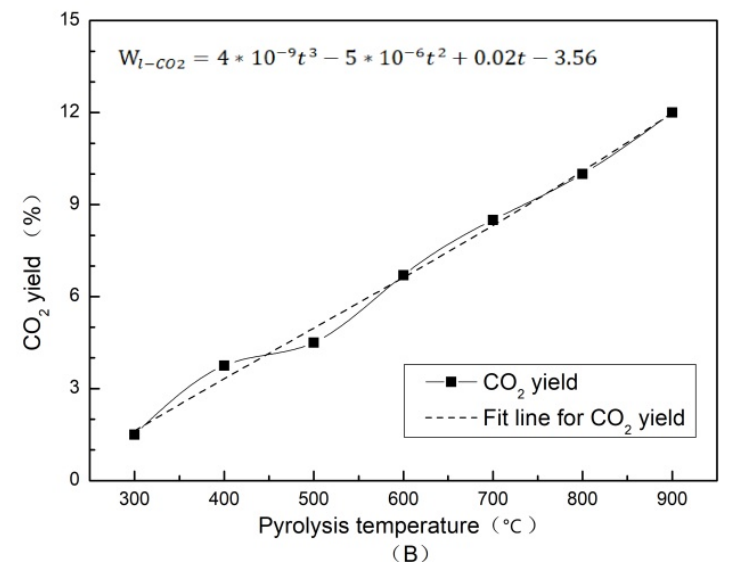

B)

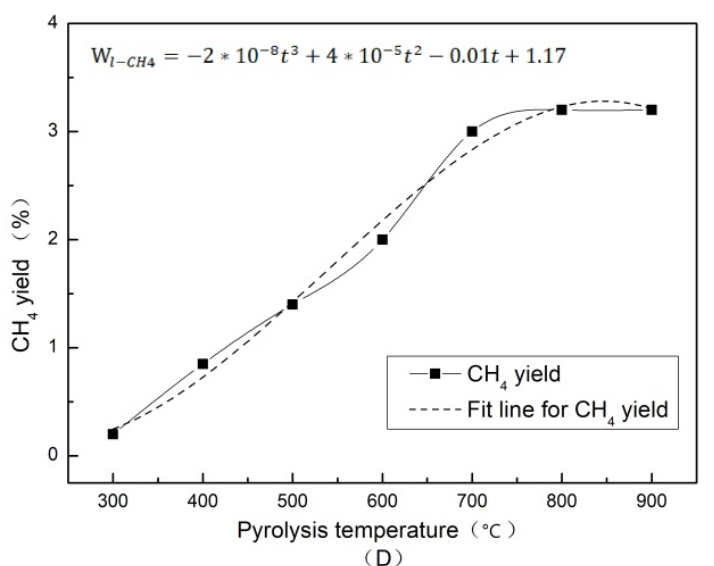

Fig. 3. The yield curve and fitting curve of lignin pyrolysis products

\section{Pyrolysis mechanism of biomass with three components}

Most of the studies focused on the pyrolysis mechanism of biomass single component $[5,6]$. The reason is that the single component pyrolysis experiment is easy to realize, but the co-pyrolysis law of biomass three components (cellulose, hemicellulose and lignin) must be considered.

In this paper, the product distribution of biomass thermal decomposition is predicted by the mass superposition method of three components. The specific algorithm is shown in equation (1). 


$$
W_{\mathrm{b}}=W_{\mathrm{c}-\mathrm{b}} x_{\mathrm{c}}+W_{\mathrm{h}-\mathrm{b}} x_{\mathrm{h}}+W_{\mathrm{l}-\mathrm{b}} x_{1}
$$

where:

$W_{\mathrm{b}}$ is the mass fraction of biomass pyrolysis product b (\%), b can be $\mathrm{CO}, \mathrm{CO}_{2}, \mathrm{CH}_{4}$ and $\mathrm{H}_{2}$;

$W_{\mathrm{c}-\mathrm{b}}$ is the mass fraction of cellulose pyrolysis product $\mathrm{b}(\%)$, b can be $\mathrm{CO}, \mathrm{CO}_{2}, \mathrm{CH}_{4}$ and $\mathrm{H}_{2}$;

$x_{\mathrm{c}}$ is percentage of cellulose in biomass $(\%)$;

$W_{\mathrm{h}-\mathrm{b}}$ is the mass fraction of hemicellulose pyrolysis product $\mathrm{b}(\%)$, b can be $\mathrm{CO}, \mathrm{CO}_{2}, \mathrm{CH}_{4}$ and $\mathrm{H}_{2}$;

$x_{\mathrm{h}}$ is percentage of hemicellulose in biomass $(\%)$;

$W_{\text {l-b }}$ is the mass fraction of lignin pyrolysis product $\mathrm{b}$ (\%), b can be $\mathrm{CO}, \mathrm{CO}_{2}, \mathrm{CH}_{4}$ and $\mathrm{H}_{2}$;

$x_{1}$ is percentage of lignin in biomass $(\%)$.

The fitting formulas of pyrolysis products and temperature obtained in Section 2 are introduced into Equation 1. The relationship between pyrolysis yields of three-component biomass and temperature can be obtained.

\section{Modification of biomass pyrolysis model used ultimate analysis}

Reference [7] established a biomass pyrolysis yield model based on ultimate analysis by using the coal gasification method. The model estimated the yield of pyrolysis products by element balance method without considering the effect of biomass components. In other words, the conclusion that heating rate and temperature have no effect on the model is contrary to the fact.

Therefore, a method was proposed to classify biomass into cork biomass, hardwood biomass and herbaceous plant biomass, and to modify the pyrolysis model of biomass by ultimate analysis for different types of biomass. Specific practices are as follows:

1) Nine biomass were selected for different types, and the average values were obtained according to the contents of cellulose, hemicellulose and lignin. The calculated results are shown in Table 1.

2 ) The average pyrolysis gas yields of cork, hardwood and herbaceous plants were obtained by substituting the typical three-component homogeneity into equation (1), as shown in Table 2.

3 ) Based on the experimental data in reference [810], the correction factors of yield of different pyrolysis components were obtained according to equation 2 and 3 . It is worth explaining that the correction factor is a function of temperature.

4) The prediction model of biomass pyrolysis gas yield by elemental analysis method was modified by using correction factor. The modified pyrolysis model was shown in table 3 .

Equation 2 is a method for calculating the average pyrolysis yield of different biomass types.

$$
\bar{W}_{j, i}=W_{c-j} \bar{x}_{c, i}+W_{h-j} \bar{x}_{h, i}+W_{l-j} \bar{x}_{l, i}
$$

Where:
$\bar{W}_{j, i}$ is average mass fraction of $j$ products produced by biomass $i$ pyrolysis (\%), $i$ can be cork, hardwood and herb, $j$ can be $\mathrm{CO}, \mathrm{CO}_{2}, \mathrm{CH}_{4}$ and $\mathrm{H}_{2}$;

$W_{c-j}$ is the mass fraction of cellulose pyrolysis product $j(\%)$;

$W_{h-j}$ is the mass fraction of hemicellulose pyrolysis product $j(\%)$;

$W_{l-j}$ is the mass fraction of lignin pyrolysis product $j$ $(\%)$

$\bar{x}_{c, i}$ is percentage of cellulose in biomass $i(\%)$;

$\bar{x}_{h, i}$ is percentage of hemicellulose in biomass $i(\%)$;

$\bar{x}_{l, i}$ is percentage of lignin in biomass $i(\%)$.

\begin{tabular}{|c|c|c|c|c|}
\hline \multicolumn{2}{|c|}{ Biomass } & Cellulose & Hemicellulose & Lignin \\
\hline \multirow{4}{*}{ Cork } & Spruce & 45.6 & 20.0 & 28.2 \\
\hline & Pine & 46.9 & 20.3 & 27.3 \\
\hline & Cryptomeria & 38.6 & 23.1 & 33.8 \\
\hline & Average & 43.7 & 21.1 & 29.8 \\
\hline \multirow{4}{*}{$\begin{array}{l}\text { Hard } \\
\text { wood }\end{array}$} & Poplar & 49.0 & 24.0 & 20.0 \\
\hline & Willow & 41.7 & 16.7 & 29.3 \\
\hline & Beech & 43.9 & 28.4 & 24.0 \\
\hline & Average & 44.9 & 23.0 & 24.4 \\
\hline \multirow{4}{*}{ Herb } & Rice husk & 37.0 & 23.4 & 24.8 \\
\hline & Corn stalks & 42.7 & 23.2 & 17.5 \\
\hline & miscanthus & 34.4 & 25.4 & 22.8 \\
\hline & Average & 38.0 & 24.0 & 21.7 \\
\hline
\end{tabular}

Table 1. Chemical composition of various biomass types (\%)

The method of calculating the correction coefficient considering the composition is shown in equation 3 . Its physical meaning is the ratio of the average yield of pyrolysis gas of different kinds of biomass to the experimental data in references.

$$
\mathrm{K}=\bar{W}_{j, i} / W_{b}
$$

Where:

$\bar{W}_{j, i}$ is average mass fraction of $\mathrm{j}$ products produced by biomass $i$ pyrolysis(\%), $i$ can be cork, hardwood and herb, $j$ can be $\mathrm{CO}, \mathrm{CO}_{2}, \mathrm{CH}_{4}$ and $\mathrm{H}_{2}$;

$W_{\mathrm{b}}$ is the mass fraction of biomass pyrolysis product b (\%), b can be $\mathrm{CO}, \mathrm{CO}_{2}, \mathrm{CH}_{4}$ and $\mathrm{H}_{2}$. 
Table 2. The mean formula of pyrolysis yield for different types of biomass

\begin{tabular}{|c|c|c|}
\hline Biomass & $\begin{array}{l}\text { Pyrolysis } \\
\text { gas }\end{array}$ & Mean formula of pyrolysis yield \\
\hline \multirow{4}{*}{ Cork } & $\mathrm{CO}$ & $\begin{array}{c}-0.74 * 10^{-7} t^{3}+1.48 * 10^{-4} t^{2}- \\
0.07 t+8.95\end{array}$ \\
\hline & $\mathrm{CO}_{2}$ & $\begin{array}{c}0.80 * 10^{-7} t^{3}-1.09 * 10^{-4} t^{2}+0.10 t- \\
16.10\end{array}$ \\
\hline & $\mathrm{CH}_{4}$ & $\begin{array}{c}-1.13 * 10^{-7} t^{3}+1.58 * 10^{-4} t^{2}- \\
0.07 t+10.05\end{array}$ \\
\hline & $\mathrm{H}_{2}$ & $\begin{array}{c}-0.09 * 10^{-7} t^{3}+1.14 * 10^{-5} t^{2}-3.5^{*} 10^{-} \\
{ }^{3} t+0.59\end{array}$ \\
\hline \multirow{4}{*}{ Hardwood } & $\mathrm{CO}$ & $\begin{array}{c}-0.75^{*} 10^{-7} t^{3}+1.50^{*} 10^{-4} t^{2}- \\
0.07 t+9.24\end{array}$ \\
\hline & $\mathrm{CO}_{2}$ & $\begin{array}{c}0.74 * 10^{-7} t^{3}-1.15 * 10^{-4} t^{2}+0.10 t- \\
16.72\end{array}$ \\
\hline & $\mathrm{CH}_{4}$ & $\begin{array}{c}-0.57 * 10^{-7} t^{3}+1.61 * 10^{-4} t^{2}- \\
0.07 t+10.30\end{array}$ \\
\hline & $\mathrm{H}_{2}$ & $\begin{array}{c}-0.09 * 10^{-7} t^{3}+1.32 * 10^{-5} t^{2}-4.35 * 10^{-} \\
{ }^{3} t+0.73 \\
\end{array}$ \\
\hline \multirow{4}{*}{ Herb } & $\mathrm{CO}$ & $\begin{array}{c}-0.69^{*} 10^{-7} t^{3}+1.37^{*} 10^{-4} t^{2}- \\
0.06 t+8.16\end{array}$ \\
\hline & $\mathrm{CO}_{2}$ & $\begin{array}{c}2.64 * 10^{-7} t^{3}-1.11 * 10^{-4} t^{2}+0.10 t- \\
15.60\end{array}$ \\
\hline & $\mathrm{CH}_{4}$ & $\begin{array}{c}-0.50 * 10^{-7} t^{3}+1.40 * 10^{-4} t^{2}- \\
0.40 t+8.94 \\
\end{array}$ \\
\hline & $\mathrm{H}_{2}$ & $\begin{array}{c}-0.08 * 10^{-7} t^{3}+1.19 * 10^{-5} t^{2}-4.03 * 10^{-} \\
{ }^{3} t+0.66\end{array}$ \\
\hline
\end{tabular}

Note: $t$ is pyrolysis temperature $\left({ }^{\circ} \mathrm{C}\right)$.

In the table $3, \mathrm{~A}, \mathrm{~B}, \mathrm{C}$ and $\mathrm{F}$ represent the yields of $\mathrm{CO}, \mathrm{CO}_{2}, \mathrm{CH}_{4}$ and $\mathrm{H}_{2}$, respectively. utl(1) and utl(2) represent the mass fractions of $\mathrm{C}$ and $\mathrm{H}$ for biomass ultimate analysis, respectively. $f=(100-\operatorname{pro}(1)) / 100$; $\operatorname{pro}(1)$ represents the moisture of the biomass proximate analysis $[11,12]$.

Table 3. The modified pyrolysis model

\begin{tabular}{|c|c|c|}
\hline Product & $\begin{array}{c}\text { Elemental analysis pyrolysis } \\
\text { model }\end{array}$ & $\begin{array}{c}\text { Modified } \\
\text { pyrolysis model }\end{array}$ \\
\hline $\mathrm{CO}$ & $\mathrm{A}=\mathrm{utl}(1)^{*} 0.01 * f^{*} 0.44^{*} 28 / 12$ & $\mathrm{~A} * \mathrm{~K}$ \\
\hline $\mathrm{CO}_{2}$ & $\mathrm{~B}=\mathrm{utl}(1)^{*} 0.01 * f^{*} 0.03 * 44 / 12$ & $\mathrm{~B} * \mathrm{~K}$ \\
\hline $\mathrm{CH}_{4}$ & $\mathrm{C}=\mathrm{utl}(2)^{*} 0.01 * f^{*} 0.17 * 4$ & $\mathrm{C} * \mathrm{~K}$ \\
\hline $\mathrm{H}_{2}$ & $\mathrm{~F}=\mathrm{utl}(2)^{*} 0.01 * f^{*} 6$ & $\mathrm{~F} * \mathrm{~K}$ \\
\hline
\end{tabular}

\section{Model verification}

In order to verify the accuracy of the model, the revised model and the pyrolysis model of elemental analysis were compared with the experimental results in Reference [13]. The composition analysis of biomass raw materials in the experiment is shown in Table 4, and the pyrolysis temperature is $500{ }^{\circ} \mathrm{C}$.

The comparison results are shown in Fig. 4 and Fig. 5. As shown in Fig. 4 and Fig. 5, the revised model is closer to the experimental value. The difference between the original model and the experimental data is large. The reason is that the original model only considers the composition of elements, but does not consider the pyrolysis law of specific components, especially the effect of temperature. When the temperature is low, the hydrocarbons with long chains can not be decomposed completely, which makes the predicted value of the original model obviously larger. The modified model is a function of temperature, which can match the experimental data better.

Compared with figs. 4 and 5 , the $\mathrm{CO}$ yield is much higher than other gases, and the $\mathrm{H}_{2}$ yield of walnut hull is lower than that of rice hull because of the high lignin content of walnut hull and the low hydrogen yield at low temperature, which is consistent with the conclusion of section 2. At low temperature, the simulation results of pyrolysis yield model of elemental analysis method are worse for the prediction of $\mathrm{CO}_{2}, \mathrm{CH}_{4}$ and $\mathrm{H}_{2}$ yields.

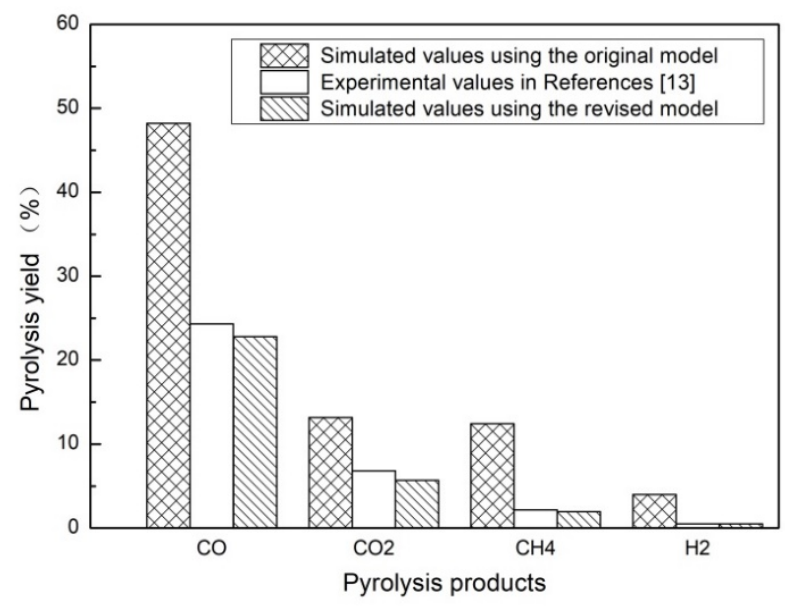

Fig. 4. Comparison of experimental data and simulation data of walnut shell pyrolysis

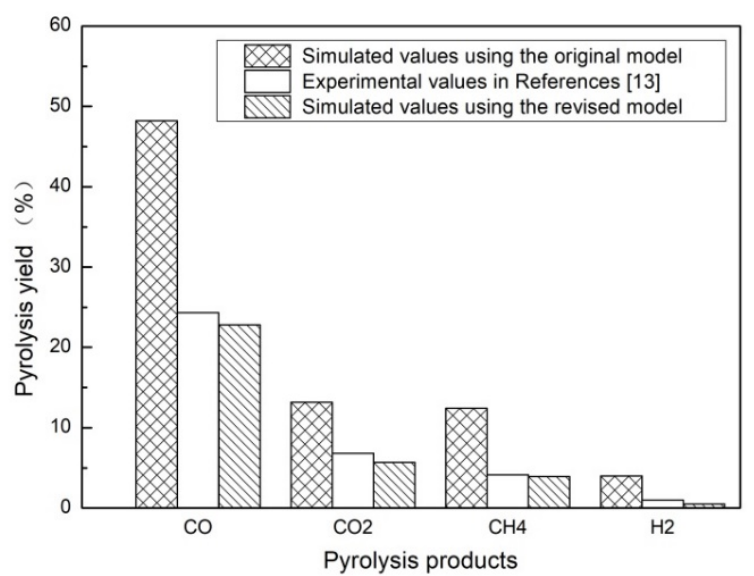

Fig. 5. Comparison of experimental data and simulation data of rice husk pyrolysis 
Table 4. Composition of biomass in pyrolysis experiment (\%)

\begin{tabular}{|c|c|c|c|c|c|c|c|c|c|c|c|c|}
\hline \multirow{2}{*}{ Biomass } & \multicolumn{4}{|c|}{ Proximate analysis } & \multicolumn{5}{|c|}{ Ultimate analysis } & \multirow{2}{*}{ Cellulose } & \multirow{2}{*}{ Hemicellulose } & \multirow{2}{*}{ Lignir } \\
\hline & $\mathrm{M}_{\mathrm{ar}}$ & $\mathrm{V}_{\mathrm{ar}}$ & $\mathrm{FC}_{\mathrm{ar}}$ & $\mathrm{A}_{\mathrm{ar}}$ & $\mathrm{C}_{\mathrm{daf}}$ & $\mathrm{H}_{\text {daf }}$ & Odaf & $\mathrm{N}_{\text {daf }}$ & $S_{\text {daf }}$ & & & \\
\hline Walnut shells & 3.73 & 74.32 & 20.98 & 0.97 & 52.62 & 5.67 & 41.25 & 0.34 & 0.11 & 45.1 & 24.2 & 23.1 \\
\hline Rice husk & 8.69 & 59.44 & 16.48 & 15.39 & 50.95 & 7.00 & 41.04 & 0.77 & 0.24 & 37.0 & 23.4 & 24.8 \\
\hline
\end{tabular}

Note: $a r$ is as received basis; daf is as dry and ash free basis.

3. P. Patwardhan, D. Dalluge, B. Shanks, et al. Distinguishing primary and secondary reactions of cellulose pyrolysis, Bioresour Technol, 102 (8) : 5265-5269 (2011)

The yield of biomass pyrolysis is related to raw material composition, heating temperature and heating rate. In this paper, the element composition and material structure are considered comprehensively. According to the pyrolysis test data of three components of biomass (cellulose, hemicellulose and lignin), the temperature variable is introduced into the original pyrolysis model of ultimate analysis, and a modified pyrolysis mechanism model is proposed. Through the research, the following conclusions are drawn.

1 ) The pyrolysis model of biomass based on ultimate analysis does not consider the influence of temperature, which is quite different from the actual pyrolysis experiment, especially the pyrolysis simulation at low temperature.

2 ) The correlations of pyrolysis mechanism of cellulose, hemicellulose and lignin were established, which were a function of temperature. At the same temperature, the pyrolysis products of biomass fuels with different component contents are also different.

3) A method was proposed to classify biomass into cork biomass, hardwood biomass and herbaceous plant biomass, and to modify the pyrolysis model of biomass by ultimate analysis for different types of biomass. Model validation shows that the revised model is closer to the experimental value.

\section{Acknowledgement}

The authors acknowledge the financial support from Hebei Natural Science Foundation Project (E2017208109).

\section{References}

1. S. Xin. Study on Thermal Decomposition and Interaction Mechanism of Biomass Based on Components, ( Huazhong University of Science and Technology,2014)

2. D. Shen, S. Gu, The mechanism for thermal decomposition of cellulose and its main products. Bioresource Technology, 100(24): 6496-6504(2009).

4. M Asmadi, H Kawamoto, S Saka. Gas- and solid/liquid-phase reactions during pyrolysis of softwood and hardwood lignins, J Anal Appl Pyrol, 92(1): 88-96 (2011)

5. D. J. Cosgrove. Re-constructing our models of cellulose and primary, cell wall assembly. Curr Opin Plant Biol, 22: 122-131(2014)

6. A. Trendewicz, R Evans, A Dutta, et al. Evaluating the effect of potassium on cellulose pyrolysis reaction kinetics, Biomass Bioenerg, 74: 15-25 (2015)

7. D. Li, H. Wang, P Han. Establishment of Fluidized Bed Biomass Gasification Kinetic Model, Journal of North China Electric Power University (Natural Science Edition), (01): 4-8 (2008)

8. Z. Si. Study on Preparation of Aromatic Hydrocarbons by Biomass Pyrolysis Gas and Methanol Catalytic Co-Cracking , ( China Agricultural University2018)

9. H. Zhang, R. Xiao, D. Wang, et al. Biomass fast pyrolysis in a fluidized bed reactor under $\mathrm{N}_{2}, \mathrm{CO}_{2}$, $\mathrm{CO}, \mathrm{CH}_{4}$ and $\mathrm{H}_{2}$ atmospheres[J]. Bioresour Technol, 102(5): 4258-4264 (2011)

10. D. Chen, A Gao, Z Ma, et al. In-depth study of rice husk torrefaction: Characterization of solid, liquid and gaseous products, oxygen migration and energy yield, Bioresour Technol , 253:148-153 (2018)

11. L. Yuan, W. Yan, F. Guo, et al. Characterization of the gas releasing behaviors of catalytic pyrolysis of rice husk using potassium over a micro-fluidized bed reactor, Energ Convers Manage, 136: 395-403 (2017)

12. D. Zhang, H. Liu, J. Hu, et al. Evolution of organic structure of thermal cracking products of walnut shell, Industrial Heating,46(04):9-13 (2017)

13. S. Ma. Biomass Pyrolysis Gas Modeling and Fractional Condensation Study. (University of Science and Technology of China,2018) 